\title{
Teaching Reform on Ancient Chinese Course under the Cultivation Mode of Applied Talents
}

\author{
Zhang Li \\ Qilu Normal University, Shandong, China, 250013
}

Keywords: the cultivation of applied talents; the ancient Chinese teaching content; teaching reform

\begin{abstract}
Under the training mode of applied talents, the ancient Chinese course must be re-audited, and the teaching content should be the foundation and key of the course audit. The ancient Chinese teaching target should be based on training target integrating knowledge, ability, and emotion; Educational materials on the basis of students and school registration need appropriate adjustments; the contents of teaching should be under the guidance of teaching objectives in respect of teaching materials, on the basis of being outstanding, intellectual, cultural, practical, innovative and interesting in order to adapt to application-based undergraduate education.
\end{abstract}

\section{Introduction}

Ancient Chinese course is an important compulsory course and basic course for Chinese language and literature major, it is not only the window of students ' understanding of the profound Chinese ancient culture, but also has countless links with modern Chinese, ancient literature, philosophy, aesthetics and other courses.

\section{Clear Teaching Objectives}

First, the systematic understanding of the ancient Chinese curriculum system, mastering the basic knowledge of classical writings; Second, to cultivate students' ability of reading ancient books, analysis ability and the phenomenon of classical Chinese writings in classical style teaching ability; Thirdly, ancient Chinese is regarded as an important window of sinology education, which enables students to critically inherit the ancient cultural heritage. Among them, the first aspect is the knowledge goal, the emphasis trains the student to remember and the understanding ability, simultaneously also realizes the second to third aspect goal the foundation. It can be divided into the ancient Chinese philology and traditional language discipline system of understanding and grasp of classical Chinese knowledge structure system, which can be in concrete teaching link to cultivate students the global consciousness, overall concept. The second aspect is the capacity goals, it also includes the need to cultivate practical ability, innovation and learning capacity. The third aspect is the emotional goal, which focuses on cultivating students ' eq and sound personality through the influence of traditional culture.

\section{Reform Teaching Content}

The content of the course objectives from students and teachers, educational content and teaching practical and comprehensive process. The teaching content should be carried out in order under the guidance of teaching goal, and the textbook is an important carrier to form the teaching content. In teaching, on the one hand, we should make use of teaching material rationally according to the goal of curriculum, select and choose the content of teaching material, on the other hand, we should scientifically process teaching material and organize the instruction rationally. In addition, this teaching material whole arranged take the literary selections primarily, ancient times Chinese general knowledge as auxiliary, and gave dual attention to the ancient times Chinese general service word system, compared with conformed to the Chinese language study specialized student to study the ancient times Chinese the custom and the basic rule. Therefore, according to the actual situation, 
we also need to solve some problems when using the textbook. First, student's capacity. As the place colleges and universities, student's receptivity is limited; Second, the school's training goals. Third, the class question. Fourth, the curriculum problems. Therefore, teaches when needs according to the above special details, arranges the course content based on the teaching material, thus the guarantee plan of instruction carries on smoothly. In view of the contents of textbooks and the actual teaching of some of the problems exposed, At the present stage, we should re-examine the content of teaching, explore the value of curriculum in many ways, and probe the way of reform.

\section{Orientation of the Course}

From the perspective of curriculum orientation, communication between ancient Chinese and modern Chinese. Ancient Chinese is the foundation of modern Chinese, and the modern Chinese language system evolved from the ancient Chinese language system. In the course of teaching, we should use these facts to explain the main points of the textbook and strengthen the close relationship with real life. This will not only stimulate students' enthusiasm for learning, but also highlight the social value of ancient Chinese courses and enhance the practical significance of ancient Chinese courses. Therefore, we must pay attention to the real social life in the teaching process, and understand the ancient Chinese knowledge which can explain the modern Chinese theory.

\section{Construction of the Knowledge System}

First of all, we should increase the arrangement of class hour. As a basic course, ancient Chinese not only imparts knowledge of ancient Chinese language, but also bears the responsibility of spreading Chinese excellent traditional culture. Therefore, in the mode of application-oriented talent cultivation, the ancient Chinese teaching should appropriately increase the teaching of literature selection, and integrate the teaching contents of the general theory into the teaching of literature and selection

Second, strengthen the ancient Chinese teaching and the primary and secondary language teaching link. In a string of old knowledge expansion on the basis of new knowledge, a comprehensive grasp of language knowledge teaching in the primary, middle and inner link, guides the student to utilize the related theory of language based on specific language phenomenon in Chinese teaching of primary and secondary schools, deepen their understanding of the importance of theoretical study, improve their professional accomplishment.

Thirdly, it is necessary to strengthen the combination of ancient Chinese language courses and other courses to cultivate students' comprehensive language ability.However, the study of ancient literature can deepen the understanding of ancient Chinese, and make the theoretical knowledge corroborated by sensibility, and the two mutually promote each other.

\section{Implementation of Cultural Perspective}

The ancient Chinese classic article mainly includes the pre-qin period's title and excellent antique works of past dynasties. They set at an organic whole, thoughts and artistry is elaborate creation of high-quality goods, the ancient astronomers and historians carried in our country's long history and splendid culture. Advocating quality-oriented education today, on the basis of students' learning stage, we should abandon the fastidious habits in overweight teaching modes, focusing on selected works of mining hidden behind the essence of Chinese traditional culture, the ancient Chinese lessons to become the window of the traditional moral culture heritage and culture personality accomplishment of main land. "ancient Chinese" is the key to open the treasure house of ancient culture. By digging and utilizing the related culture in the teaching, the dull language law is put in a splendid cultural background and makes it interesting. This can not only expand the knowledge of the students, but also stimulate their enthusiasm for learning. The most important thing is to enable students to understand China's long and splendid cultural tradition and carry it forward. 


\section{Strengthen the Teaching Practice}

First, do the original reading. The so-called original reading is to allow students to read the text of the classical texts in the textbook before and after class. Increase the amount of reading the original works of ancient, from two aspects of intensive reading and extensive reading to strict training, and encourage students extracurricular reading the original works of ancient books, read it, especially in "zuo zhuan" can not only familiar with the language of the pre-qin period, but also can get a lot of the pre-qin historical, social, standard system, customs, thoughts of flesh and blood of knowledge" (qiu xigui 2012).

Secondly, carry out teaching practice. Let the student to choose the appropriate selection of the teaching practice, the organization students lectures on the stage, let the student prepares for his lectures, and evaluation, on the one hand can promote students in-depth understanding of the teaching content, what is more important for students to teachers' qualification examinations in the interview process, and to lay a solid foundation for the future engaged in Chinese teaching.

\section{Improve Interest and Encourage Innovation}

Innovative attitude and innovative ability is a kind of quality, it requires people to have a critical spirit, always pursuing the lofty realm, moment there is a kind of beyond the target. The applied undergraduate colleges must consider the problem from the level of the talent training plan, need to set up the innovative education idea, reform in many aspects of the education and teaching, and put forth efforts to cultivate the innovative quality of the students ' creative thinking mode, consciousness and ability. Under the new situation, we initiate the teacher to be supposed to become offering a few ordinary introductory remarks so that others may offer their valuable ideas, takes the valuable question, places in the classroom to carry on the centralism solution and the discussion. Requires teachers to expand horizons, update the concept of talent, establish a multivariate evaluation mechanism, active classroom atmosphere.

\section{Conclusion}

In a word, the reform of ancient Chinese teaching content is to get rid of the traditional teaching mode and make the learning style more diversified. It aims to establish a teaching system with feedback function, incentive function and control function from the two perspectives of "teaching" and "learning" of students. Realize the transformation from traditional knowledge paradigm to new capacity paradigm. This has a positive effect on improving classroom efficiency and promoting students' multi-faceted ability.

\section{Acknowledgement}

This paper is a phased research achievement of Qilu Normal University's teaching reform research project (project number: jg201705).

\section{References}

[1] Guo Xiliang, Tang Zuofan, He Jiuying, etc. Ancient Chinese (Revised Edition) [M]. Beijing: Commercial Press, 2015.

[2] Wang Li. Ancient Chinese (classical edition) [M]. Beijing: Zhonghua Book Company, 2016. 